\title{
APLIKASI ONLINE MOBILE REPOSITORY SYSTEM
}

\author{
Michael Yoseph Ricky \\ Computer Science Department, School of Computer Science Binus University \\ Jl. K.H. Syahdan No. 9, Palmerah, Jakarta Barat 11480 \\ mricky@binus.edu
}

\begin{abstract}
In order to support the decision making process effectively and efficiently, a lot of companies invest in information technology for data management and storage. The information technology is emphasized in data storage of daily transactions in large numbers in a medium, so that data can be easily processed. Online Mobile Repository System is a system that uses a temporary storage system which is practical and can be accessed online. Thus, the system simplifies data access and organization anywhere and anytime. The design of this system uses the methods of literature review, interviews, field studies, and combined design studies. The research results in a data storage system which is organized, safe and structured to support the meeting process.
\end{abstract}

Keywords: data management and storage, online mobile repository system, temporary storage system

\begin{abstract}
ABSTRAK
Agar dapat mendukung proses pengambilan keputusan yang efektif dan efisien, banyak perusahaan menginvestasikan dana pada teknologi informasi untuk pengelolaan dan penyimpanan data. Teknologi informasi tersebut ditekankan pada penyimpanan data hasil transaksi sehari-hari dalam jumlah besar dalam suatu media, sehingga data dapat dengan mudah diolah. Online Mobile Repository System merupakan suatu sistem yang menggunakan metode penyimpanan sementara yang praktis dan dapat diakses secara online. Sistem ini mempermudah user mengakses dan mengorganisasi data dimanapun dan kapanpun. Perancangan sistem ini menggunakan metode studi kepustakaan, wawancara, studi lapangan, dan studi perancangan gabungan. Hasil penelitian yang dicapai adalah sistem penyimpanan data yang terorganisir, aman dan terstruktur untuk mendukung proses rapat.
\end{abstract}

Kata kunci: pengelolaan dan penyimpanan data, online mobile repository system, metode penyimpanan sementara 


\section{PENDAHULUAN}

Penggunaan teknologi dibidang jaringan sekarang ini sudah semakin luas, mencakup lokal, corporation, hingga enterprise. Hal tersebut bisa terjadi karena kebutuhan manusia terus dan terus meningkat. Oleh sebab itu, harus ada infrastuktur yang kuat didalam sebuah perusahaan baik yang kecil, menengah, maupun besar. Perusahaan baik yang besar maupun kecil, tidak lepas dari penggunaan data. Karena data adalah hal yang sangat penting didalam sebuah perusahaan. Oleh karena itu, perusahaan harus memiliki proses aliran data yang baik.

Dalam penerapannya, masih banyak perusahaan-perusahaan yang belum menggunakan sistem yang baik dalam mengelola aliran data yang ada didalam perusahaan tersebut. Hal tersebut dapat merugikan perusahaan tersebut seperti memperlambat kinerja perusahaan, mengurangi tingkat produktivitas perusahaan, dan banyak hal lainnya. Mungkin hal-hal yang merugikan tersebut tidak terlihat ataupun dirasakan secara langsung oleh perusahaan, tapi lama kelamaan data yang digunakan semakin banyak dan beban yang ditanggung sistem semakin banyak, pada akhirnya perusahaan akan merugi dan mengalami banyak masalah.

Dalam rapat maupun seminar dalam sebuah perusahaan, biasanya terjadi banyak pertukaran data perusahaan baik yang bersifat umum, penting, bahkan rahasia. Apalagi bila rapat maupun seminar tersebut dilakukan diluar dari lokasi perusahaan dan data perlu diakses secara bersama-sama, penyimpanan data sulit untuk dilakukan.

Apabila anggota rapat seluruhnya harus mendownload file-file tersebut dari server perusahaan melalui koneksi internet, selain koneksi internet yang up and down dengan trafik yang tidak menentu, juga akan dibutuhkan bandwidth yang besar di server karena diakses sekaligus oleh banyak orang yang tergantung dari jumlah anggota rapat. Begitu juga dengan upload file yang dilakukan melalui koneksi internet, dimana user merasa hal tersebut kurang aman.

Untuk itu, sangatlah dibutuhkan suatu metode penyimpanan sementara yang praktis dan bisa dibawa-bawa melalui internet/server yang memiliki tingkat keamanan (network security) yang baik. Data yang hendak digunakan di-download terlebih dahulu ke mobile server berupa laptop, sehingga server tersebut bisa dibawa-bawa sesuai dengan keinginan pengguna (pimpinan rapat). Dalam hal ini klien (anggota rapat) juga dapat men-download data dari mobile server lebih cepat daripada mendownload langsung dari server.

\section{Tinjauan Pustaka Network}

Network atau jaringan komputer adalah interkoneksi antara sekumpulan komputer yang melakukan komunikasi serta sharing informasi dan hardware seperti printer, scanner, modem dan peripheral lainnya. (Tanenbaum, 1997, p.2)

Manfaat jaringan komputer dalam sebuah organisasi yaitu: (1) resource sharing yang bertujuan agar seluruh program, peralatan khususnya data bisa digunakan oleh setiap orang yang ada pada jaringan tanpa terpengaruh oleh lokasi resource dan pemakai sendiri; (2) untuk menghemat biaya, contohnya perancangan sistem untuk membangun sistem yang terdiri dari komputer-komputer pribadi (model client-server) untuk menggantikan mainframe yang relatif lebih mahal; (3) untuk mendapatkan reliabilitas yang tinggi dengan memiliki sumber-sumber alternatif persediaan, misalnya semua data dapat disalin ke dua atau tiga mesin sehingga jika salah satu mesin tersebut tidak dapat dipakai atau mengalami gangguan, maka salinan lainnya dapat digunakan; (4) skalabilitas, yaitu 
kemampuan untuk meningkatkan kinerja sistem secara berangsur-angsur sesuai dengan beban pekerjaan dengan menambahkan sejumlah processor.

\section{Topologi Jaringan}

Topologi jaringan adalah penempatan hubungan antara elemen-elemen yang ada pada jaringan terutama secara physical (nyata) dan logical (virtual). Topologi jaringan dibagi menjadi dua, yaitu: (1) physical topology (topologi fisik) adalah gambaran nyata secara fisik dalam suatu jaringan dimana ada dua atau lebih alat yang saling berhubungan; (2) logical topology adalah gambaran secara virtual atau maya bagaimana sebuah host dapat melakukan komunikasi dengan menggunakan medium. Bentuk umum yang biasa digunakan dalam Logical topology adalah Broadcast dan Token Passing.

\section{Broadcast}

Jaringan broadcast memiliki jalur komunikasi tunggal yang digunakan oleh semua mesin atau device yang ada pada sebuah jaringan (Tanenbaum, 2000, p.15). Pada topologi broadcast, setiap host yang mengirimkan paket data akan mengirimkan paket tersebut ke semua host secara broadcast pada media komunikasi pada jaringan tersebut.

\section{Token Passing}

Token Passing merupakan proses dimana beberapa komputer melakukan transmisi paket data pendek yang disebut token secara bergantian. Pada topologi ini, setiap host mempunyai kemampuan untuk mengendalikan akses jaringan dengan mem-pass-kan atau melewatkan token elektronik yang secara sekuensial akan melalui masing-masing host dari jaringan tersebut. Ketika sebuah host menerima token tersebut, berarti host tersebut diijinkan untuk mengirimkan data pada jaringan tersebut. Jika host tersebut tidak memiliki data yang akan dikirim, token akan dilewatkan ke host berikutnya. Kejadian tersebut akan terus menerus dilakukan (Tanenbaum, 2000, p.67).

\section{Protokol}

Protocol adalah sebuah standar atau aturan yang mengatur terjadinya hubungan komunikasi dan perpindahan paket data antara dua atau lebih titik komputer. Protocol dapat diterapkan pada perangkat keras (hardware) atau perangkat lunak (software) maupun kombinasi dari keduanya. Pada tingkatan yang terendah, protocol mendefenisikan koneksi perangkat keras.

Jenis-jenis protocol pada umumnya adalah: (1) IP (Internet Protocol) - merupakan suatu metode atau protokol yang berfungsi mengatur bagaimana suatu data dikirim dari satu komputer ke komputer lain dalam jaringan komputer. Setiap perangkat keras komputer (host) yang berada dijaringan internet memiliki setidaknya satu alamat IP (IP address) yang bersifat unik yang membedakan host tersebut dengan host lain; (2) FTP - sebuah protokol internet yang berjalan di dalam lapisan aplikasi yang merupakan standar untuk mengirimkan file komputer antar mesin-mesin dalam sebuah internetwork. FTP bertujuan untuk transfer suatu file atau bagian dari file dengan memakai FTP command (Lukas, 2000, p.249); (3) TCP berfungsi untuk mengubah suatu blok data yang besar menjadi segmen-segmen yang dinomori dan disusun secara berurutan agar si penerima dapat menyusun kembali segmen-segmen tersebut seperti waktu sebelum dikirim; (4) UDP bergantung pada lapisan atas untuk mengontrol kebutuhan data. Karena penggunaan bandwidth yang efektif, UDP banyak digunakan untuk aplikasi-aplikasi yang tidak peka terhadap penggunaan jaringan seperti SNMP dan TFTP; (5) SNMP (Simple Network Management Protocol) - network dan distribution processing berkembang pesat. Karena itu, perlu suatu sistem protokol yang mengatur sistem network yang ada dengan aplikasi-aplikasi terdistribusi. Fungsi protokol ini adalah menyederhanakan sistem network yang kompleks menjadi lebih sederhana (Lukas, 2000, p.246); (6) DHCP - merupakan protokol yang berbasis arsitektur client/server yang dipakai untuk memudahkan pengalokasian IP 
address secara otomatis dari server DHCP. DHCP memungkinkan sebuah komputer untuk berpindah ke sebuah jaringan baru dan mendapatkan konfigurasi terhadap informasi tanpa membutuhkan seorang administrator untuk membuat perubahan ke basis data (Comer, p630, 2004); (7) TELNET - adalah sebuah protokol jaringan yang digunakan pada koneksi internet atau Local Area Network. TELNET dikembangkan pada 1969 dan distandarisasi sebagai IETF STD 8, salah satu standar internet pertama. TELNET memiliki beberapa keterbatasan yang dianggap sebagai resiko keamanan. TELNET menyediakan kemampuan remote logon (remote logon capability) yang memungkinkan seorang user pada sebuah terminal atau PC untuk logon ke sebuah komputer ditempat lain dan menggunakan seolah-olah terhubung secara langsung ke komputer tersebut (Stallings, 2000, p.60); (8) HTTP adalah protokol yang digunakan untuk mengakses data dalam world wide web (WWW). Protokol ini adalah protokol ringan, tidak berstatus dan generik yang dapat digunakan berbagai macam tipe dokumen. Untuk menyediakan reliability HTTP menggunakan TCP (Forouzan, 2003, p.731) .

\section{Repository}

Repository adalah pusat lokasi untuk mencari dan mengakses informasi dari berbagai sumber seperti internet, intranet, perusahaan, database dan berbagai system penyimpanan file, yang secara efesien dan cepat dapat mendistribusikan informasi (Turban et al, 2006, p.382).

Dalam bahasa yang berbeda, Laudon (2004, p.319) mendefinisikan repository sebagai kumpulan pengetahuan internal dan eksternal di dalam lokasi tertentu untuk lebih efisien dalam hal penggunaannya bagi manajemen di dalam sebuah organisasi.

\section{Virtual Private Network (VPN)}

Menurut Stallings (2000) Virtual Private Network (VPN) adalah sebuah jaringan private (pribadi) yang dibuat di dalam jaringan public (umum) dengan menggunakan internet sebagai media komunikasinya. Apabila kita jabarkan berdasarkan suku katanya maka pengertian VPN adalah:

Virtual: tidak ada koneksi jaringan secara langsung antara dua atau lebih komputer, melainkan hanya ada koneksi vitual yang disediakan oleh VPN software melalui koneksi internet.

Private: hanya anggota dari badan/organisasi/perusahaan yang menggunakan VPN tersebut yang dapat melakukan akses dan transfer data. VPN menggunakan proses tunneling (Gambar 1) yang meliputi authentication, encapsulation dan encryption yang berperan penting dalam terbentuknya solusi komunikasi VPN yang aman.

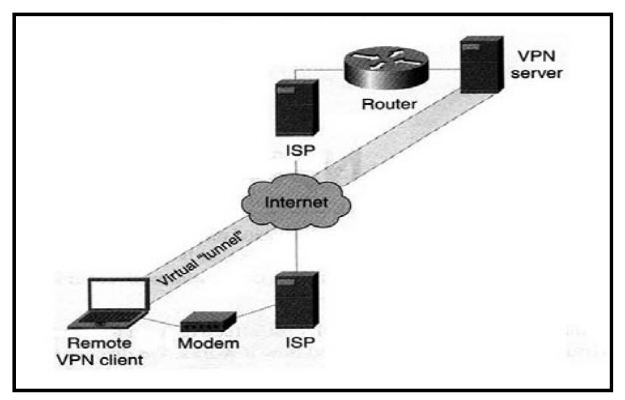

Gambar 1. Tunneling melalui jaringan.

VPN terdiri dari 2 jenis dibagi berdasarkan metode aksesnya, yaitu: (1) remote access VPN, yang memungkinkan akses kapan saja dan dimana saja ke jaringan perusahaan/kantor. Jaringan ini biasa digunakan atau diminta oleh pegawai perusahaan yang bepergian jauh tetapi ingin selalu terhubung dengan jaringan perusahaannya; (2) site-to-site VPN, disebut juga router-to-router VPN, merupakan salah satu alternatif infrastruktur WAN yang biasa digunakan.VPN jenis ini 
menghubungkan dua atau lebih kantor cabang, kantor pusat, ataupun partner bisnis ke seluruh jaringan perusahaan.

\section{Keamanan Jaringan}

Untuk menjamin keamanan ketika transfer data terjadi, khususnya transfer data antara server dengan mobile repository storage, maka jaringan komunikasi dilakukan dengan penggunaan virtual private network (VPN). Alasannya karena VPN dapat membentuk koneksi jarak jauh seolah-olah menjadi koneksi lokal dengan membuat terowongan (tunnelling) di jaringan internet. Dalam hal ini kami menggunakan OpenVPN karena merupakan software open source dan gratis.

OpenVPN juga menggunakan metode enkripsi SSL/TLS dan mempunyai kekuatan enkripsi yang kuat yaitu 1024bit yang merupakan tertinggi dikelasnya. OpenVPN juga mampu menembus NATs dan Firewall. Untuk meningkatkan keamanan di sisi klien, client openVPN juga dilengkapi dengan password untuk mencegah akses dari orang yang tidak bertanggungjawab.

Dalam sistem yang baru, user terlebih dahulu men-download data untuk rapat dari main repositori di server melalui VPN (internet), download data tersebut bisa dilakukan kapan saja, tidak harus ketika rapat akan dimulai, sehingga tidak memakan waktu ketika rapat.

Setelah data tersebut berada dalam laptop user ketika rapat dimulai, anggota rapat (klien) akan diberikan akun untuk melakukan login ke dalam program mobile repository yang dimiliki oleh user. Masing-masing akun sudah diberi hak akses oleh user. Jadi anggota rapat tidak dapat mengakses semua file yang ada tergantung dari hak akses yang diberikan kepadanya.

Apabila di dalam rapat, user memberikan tugas kepada sebagian anggota rapat untuk melakukan editing terhadap suatu file. Ketika rapat selesai file-file tersebut di-upload oleh anggota rapat ke user. Kemudian ketika rapat selesai, user akan melakukan organisir file yang ada. Apabila ada file yang perlu di-update ke server, user akan meng-upload file tersebut dengan mengakses main repository program di server dengan VPN (internet). Untuk lebih jelasnya, lihat Gambar 3.

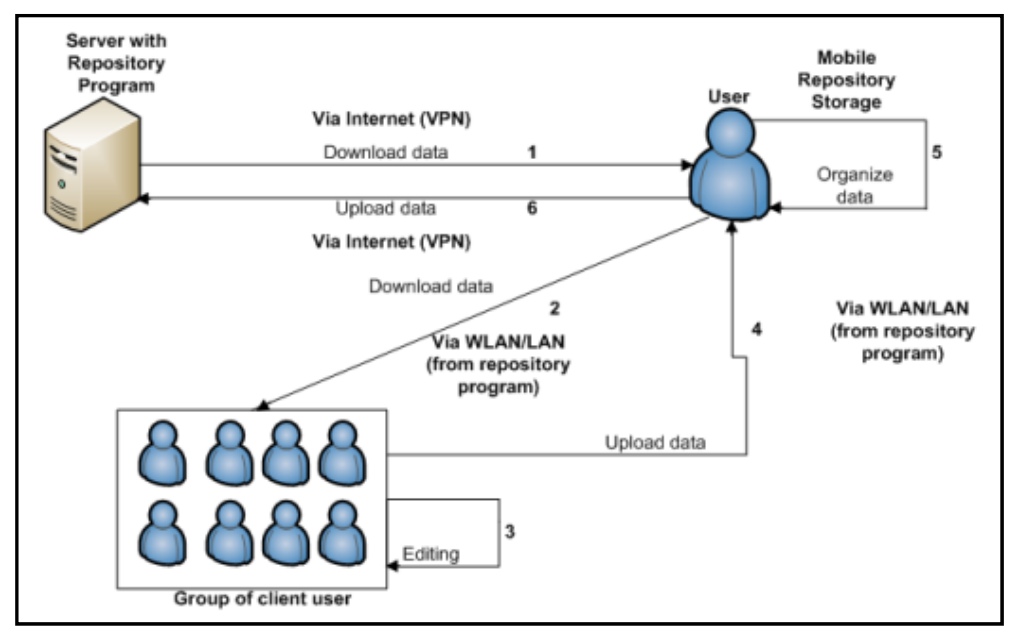

Gambar 3. Rancangan Online Mobile Repository.

\section{Online Mobile Repository System}

Online Mobile Repository System yang dibangun dengan bahasa scripting PHP. Pembuatan web ini dimaksudkan untuk mempermudah user dalam mengakses dan mengatur data yang disimpan 
pada server. Fasilitas-fasilitas yang disediakan antara lain: membuat direktori (create directory), mengubah nama file (rename), menghapus file (delete), meng-upload file (upload), membuat archive (archive), extract archive (extract), treeview, dan multiuser.

\section{Implementasi}

Implementasi pembuatan mobile repository network system (Gambar 4) dibuat dalam sebuah simulasi, yang terdiri dari: (1) server - Laptop ACER core duo $1.66 \mathrm{Ghz}$, RAM 1.5 Gbyte, HDD 60 Gbyte, menggunakan operating system CentOs 5. Server digunakan sebagai media penyimpanan akhir dan server openVPN (VPS). Di dalam laptop sudah ter-install program DeMary v1.0 (main) sebagai media organisir data, serta aplikasi openVPN GUI untuk klien; (2) mobile repository - Laptop Hp Compaq Pressario v3300 Core 2 Duo 2.1 Ghz, RAM 2 Gbyte, HDD 60 Gbyte menggunakan operating system Windows XP Home Edition 32bit. Di dalam laptop sudah ter-install program DeMary v1.0 (mobile) sebagai media organisir data, serta aplikasi openVPN GUI untuk klien; (3) Dua klien - Klien 1 adalah laptop Hp pavillion 2114tx core 2 duo 2.1 Ghz, RAM 2 Gbyte, HDD 250 Gbyte, menggunakan operating system Windows 7; Klien 2 adalah Laptop Sony Vaio pvcea16fg Core i5 2,4 Ghz, RAM 4 Gbyte, HDD 500 Gbyte, juga menggunakan operating system Windows 7.

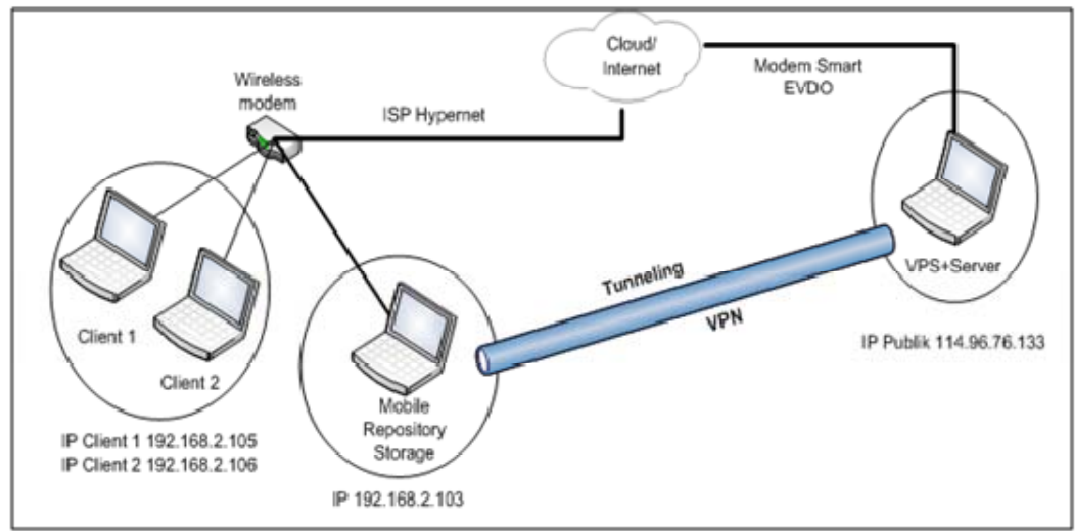

Gambar 4. Mobile network repository system.

\section{Evaluasi}

Berdasarkan hasil dari simulasi, mobile network repository system bekerja sesuai dengan yang direncanakan. Mobile network repository system berhasil memberikan akses data yang lebih cepat (reliable), organisir file yang lebih mudah (portable), dan meningkatkan keamanan transfer data ke maupun dari server (security). Ada beberapa bagian yang mengalami perubahan kecil seperti penambahan proses autentikasi pada openVPN client dan penambahan hak akses level 2 sesuai dengan permintaan user (Tabel 1).

Table 1

Detail Perubahan dari Sistem Lama ke Sistem Baru

\begin{tabular}{lcc}
\hline \multicolumn{1}{c}{ Keterangan } & $\begin{array}{c}\text { Sistem } \\
\text { Lama }\end{array}$ & $\begin{array}{c}\text { Sistem } \\
\text { Baru }\end{array}$ \\
\hline $\begin{array}{l}\text { Kecepatan download } \\
\text { data dalam rapat }\end{array}$ & $\begin{array}{c}60-110 \\
\mathrm{kbps}\end{array}$ & $\begin{array}{c}2.5-3 \\
\mathrm{mbps}\end{array}$ \\
\hline $\begin{array}{l}\text { Keamanan transfer } \\
\text { data }\end{array}$ & - & VPN \\
\hline Hak Akses Data & Level 1 & Level 2 \\
\hline
\end{tabular}


Setelah melakukan demo dengan user, tanggapan user cukup baik. User sudah cukup puas dengan sistem yang ditawarkan, tetapi memberikan sedikit request untuk lebih menyempurnakan sistem ini.

\section{PENUTUP}

Online Mobile Repository System memiliki peranan penting dalam menyediakan berbagai informasi yang dibutuhkan manajemen untuk memberikan kemudahan dalam penyimpanan, organisasi, dan data sharing. Proses implementasi Online Mobile Repository System mempercepat proses upload dan download data secara aman dan nyaman, dengan tingkat keamanan yang lebih baik terhadap data user khususnya ketika transfer data melalui internet. Online mobile repository system memudahkan user dalam mengorganisasi data yang ada.

\section{DAFTAR PUSTAKA}

Forouzan, Behrouz A. (2003). Data Communications and Networking, (3rd ed.). New York: McGrawHill.

Stallings, William. (2000). Data and Computer Communications, (6th ed.). New Jersey: Prentice Hall.

Tanenbaum, Andrew S. (2003). Computer Networks, (4th ed.). New Jersey: Prentice Hall.

Turban, E., Leidner, D., McLean, E., dan Wetherbe, J. (2006). Information Techonology for Management, (5th ed.). New York: John Wiley \& Sons. 